\title{
Comparison between Fecal Occult Blood (FOB) Device with Ziehl- Neelson (Z.N) Stain and Polymerase Chain Reaction (PCR) Techniques in the Diagnosis of Early Pulmonary Tuberculosis (PTB)
}

\author{
Yousif M Alobaid ${ }^{1}$, Amani S Elsheikh ${ }^{2}$, Mosab Nouraldein Mohammed Hamad ${ }^{3 *}$, Mogahid M. El Hassan ${ }^{4}$
}

\author{
${ }^{1}$ Department of Microbiology, Faculty of Medical Laboratory Sciences, University of El Imam El Mahdi, Sudan \\ ${ }^{2}$ Soba Teaching Hospital, Registrar of Pediatrics, Khartoum, Sudan \\ ${ }^{3}$ Phylum of Medical Parasitology, Medical Laboratory Sciences Department, Faculty of Health Science, Elsheikh Abdallah Elbadri \\ University, Berber, Sudan \\ ${ }^{4}$ Department of Clinical Laboratory Sciences, College of Applied Medical Sciences, Taibah University, KSA
}

DOI: $10.36348 /$ sjpm.2021.v06i01.001

| Received: 18.11 .2020 | Accepted: 24.12.2020 | Published: 01.01.2021

*Corresponding author: Mosab Nouraldein Mohammed Hamad

\section{Abstract}

The aim of this study was to evaluate the sensitivity of Fecal Occult Blood (FOB) strips in the diagnosis of Pulmonary Tuberculosis (PTB) isolated from sputum of tubercles patient. The study was carried out in Omdurman Teaching Hospital-Abu Anga-Tuberculosis ward. From 27th of August to 25th of September 2007. A total of 67 sputum samples collected from the suspected people. The samples examined by FOB test and Z.N techniques. Ten out of the enrolled samples, which showed positive FOB and negative Z.N techniques selected confirmed by using PCR techniques. The result showed that there were $12(17.9 \%)$ of cases were Z.N (+ve), while $55(82.1 \%)$ of cases were Z.N (-ve). It was also showed that there were 53(79.1\%) of cases were FOB test (+ve), while 14(20.9\%) of cases were FOB test (-ve). According to PCR techniques, after performed 10 samples that showed Z.N (-ve) and FOB test (+ve), it was noted that there were $4(40 \%)$ of cases were PCR (+ve), while 6(60\%) of cases were PCR (-ve).

Keywords: Sensitivity, FOB Strips, Pulmonary Tuberculosis, PCR, Sudan.

Copyright (C) 2021 The Author(s): This is an open-access article distributed under the terms of the Creative Commons Attribution 4.0 International License (CC BY-NC 4.0) which permits unrestricted use, distribution, and reproduction in any medium for non-commercial use provided the original author and source are credited.

\section{INTRODUCTION}

The World Health Organization (WHO) recommends the household tuberculosis (TB) contact investigation in low-income countries, but most contacts do not complete a full clinical and laboratory evaluation [1].

Recently, there has been an increase in cases of tuberculosis that may give to the increase in tuberculosis infection in, an increase in HIV infection, increase number of homeless people and the appearance of drug-resistance strains of tuberculosis [2].

The symptoms of people who have a pulmonary TB are, hemoptysis (coughing up blood), fatigue, weight loss, fever and night sweats, phlegmproducing cough, wheezing, chest pain, and breathing difficult [3].

The diagnosis of pulmonary tubercle patient by many ways, the tests may include: Microscopic examination, these by using Zeihl-Neelsen (Z.N)
Staining techniques for sputum or other smear suspected, Culture techniques, these for culturing Sputum. Tuberculin skin test, these used to check the patients if exposed to TB or not. Serological tests, as immuno-chromatographic strips (ICTs), DNA detection, these by using Polymerase Chain Reaction (PCR). Chest X-rays, these conduct by pictorial of the lungs. Bronchoscopy, interferon (IFN)-Gamma blood test, and Rarely, biopsy of the affected tissues (lungs and lymph nodes) [2].

\section{Rationale}

New strategies required to diagnose early cases of pulmonary tuberculosis to avoid the progress of a disease as well as Zeihl-Neelsen techniques with a sensitivity of $70 \%$, but a $30 \%$ considered as misdiagnosed. So detection of occult blood in sputum of pulmonary tuberculosis patients may offer a suitable test for early diagnosis.

\section{MATERIALS AND METHODS}

A cross-sectional study designed to target a 67 suspected people who present with signs and symptoms 
Yousif M Alobaid et al; Saudi J Pathol Microbiol, Jan, 2021; 6(1): 1-4

of pulmonary tuberculosis and referred to the TB laboratory aiming to detect Mycobacterium tuberculosis bacilli in their sputum specimens. Data collected using standard questionnaire.

\section{Methods of Zeihl-Neelsen Techniques}

Thin smears prepared, air-dried, then it covered by carbol-fuchsin (appendix 1-1) for $5 \mathrm{~min}$ and heated with flame without boiling, then the smears washed by tap water and then decolorized by $20 \%$ sulphoric acid (appendix 1-2) for $5 \mathrm{~min}$ and washed by tap water and then methylene blue (appendix 1-3) was poured for 3 seconds then washed by tap water and finally examined microscopically under oil immersion for AFB.

\section{Occult Blood Test}

This is conduct by using Umedic One Step Cassette Style Fecal Occult Blood (FOB) test (appendix 2-2). As follows; the patients were instructed to get early morning sputum in a clean, wide leak-proof container. 3-5 loop full (appendix 2-1) of samples taken and emulsified into $2 \mathrm{ml}$ of buffer solution (appendix 21) Then it shaken well and transferred 3-4 drops from the suspension to the well of the device. Then the sample was left 5-10 min and matched the test band with control band (Fig 1 and 2).

\section{Polymerase Chain Reaction (PCR)}

There are many types of PCR, each of them has steps including DNA extraction (appendix 3-1) and then PCR machine (appendix 3-4).

\section{Method of PCR}

The solution (DNGTM) (appendix 3-1) was at $37^{\circ} \mathrm{C}$ in water bath for 30 seconds and safety shake. Then the Eppendorf tube (1.5) labelled by the No. of sample, then it homogenized by using vortex for several seconds and shaked well. $100 \mu \mathrm{l}$ of sample taken into the labelled Eppendorf tube (1.5). Then $400 \mu 1$ of DNG solution added to each sample, and shaked well and centrifuged at $12.000 \mathrm{rpm}$ for $10 \mathrm{~min}$. Then $300 \mu \mathrm{l}$ of Isopropanol added and shaked gently and centrifuged. The supernatant discarded. Then $1 \mathrm{ml}$ of $75 \%$ ethanol (appendix 3-8) added to each sample and gently shaked and centrifuged at $12.000 \mathrm{rpm}$ for $5 \mathrm{~min}$ (as washed for 2-3times), then the samples blotted by using tissue paper. The water bath $\left(65^{\circ} \mathrm{c}\right)$ was used to dry the pellet of DNA for 5 min then $50 \mu$ l of D.W added, then vortex and centrifugation for 30 seconds done. The pellet of sample put in the PCR machine (Fig-3) and left up to complete the PCR cycles (appendix3-4). Then master mix (appendex $3-3),(1.5 \% \mathrm{w} / \mathrm{v})$ agarose (gel), $10 \%$ TBE (appendix 3-6), and 10\% Ethidium bromide fluorescent dye (appendix 3-7) ready. The $10 \% \mathrm{TBE}$ poured to the gel and $10 \%$ of fluorescent dye added. Then $3 \mu 1$ of methylene blue (appendix 1-3) dye taken and put into a well of a micro-titrate plate, then $7 \mu$ l of the sample taken and mixed well with dye and transferred to the gel cell up to $30 \mathrm{~min}$ at 50 volts. The result read by transferred it to the Gel documentation system by using UV light as in (Fig-4) Photo get out by computer as in (Fig-3).

\section{RESULTS}

This survey performed in Omdurman Teaching Hospital-Abu Anga - Unit of Tuberculosis. 67 suspected individuals included in the study and the results showed that: According to Z.N techniques, it noted that there were $12(17.9 \%)$ of cases were Z.N (+ve), while $55(82.1 \%)$ of cases were Z.N (-ve) as in table 1. According to FOB test, it was noted that there were $53(79.1 \%)$ of cases were FOB test (+ve) (Fig-2), while $14(20.9 \%)$ of cases were FOB test (-ve) (Fig-1) as in Table-2. According to PCR techniques, after performed 10 samples that showed Z.N (-ve) and FOB test (+ve), it was noted that there were $4(40 \%)$ of cases were PCR (+ve), while $6(60 \%)$ of cases were PCR (-ve) as in Table-3.

Table-1: Shows the result of Z.N techniques of 67 patients

\begin{tabular}{|l|l|l|}
\hline The result & No. of patients & percentage \\
\hline Positive & 12 & $17.9 \%$ \\
\hline Negative & 55 & $82.1 \%$ \\
\hline
\end{tabular}

Table-2: Shows the result of FOB test of 67 patients

\begin{tabular}{|l|l|l|}
\hline The result & No. of patients & percentage \\
\hline Positive & 53 & $79.1 \%$ \\
\hline negative & 14 & $20.9 \%$ \\
\hline
\end{tabular}

Table-3: Shows the result of PCR techniques of ten patients

\begin{tabular}{|l|l|l|}
\hline The result & No. of patients & percentage \\
\hline Positive & 4 & $40 \%$ \\
\hline negative & 6 & $60 \%$ \\
\hline
\end{tabular}

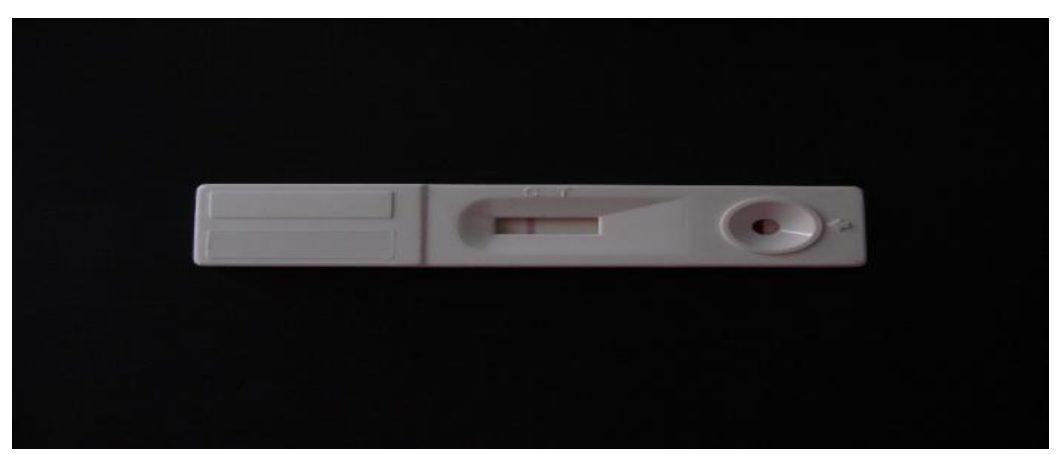

Fig-1: Negative control band (C) only 


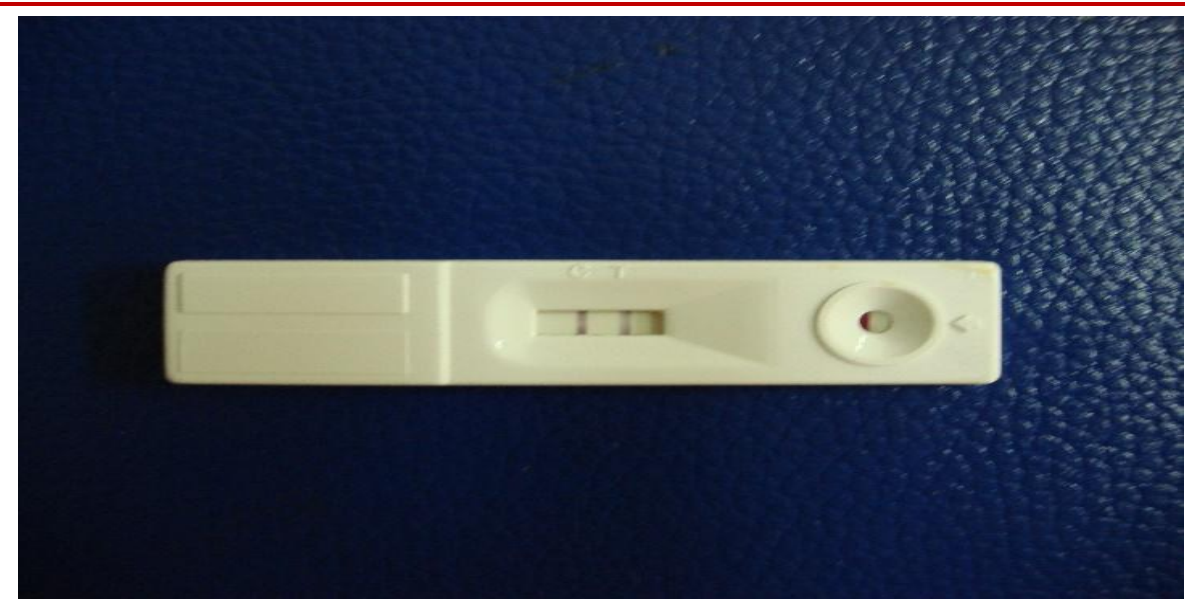

Fig-2: Positive control band (C) and test band (T) both

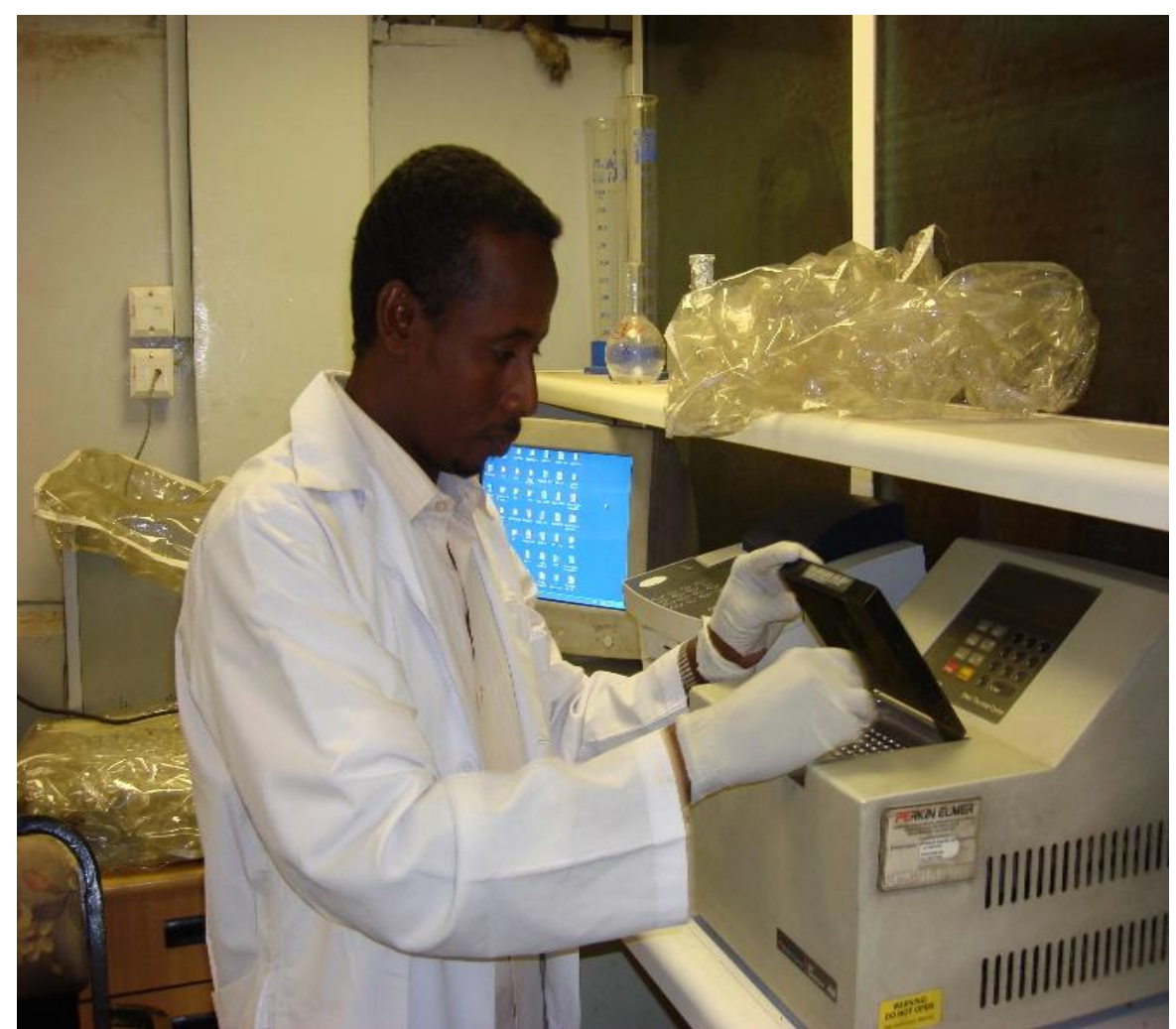

Fig-3: Shows putting the samples into DNA Thermo cycler

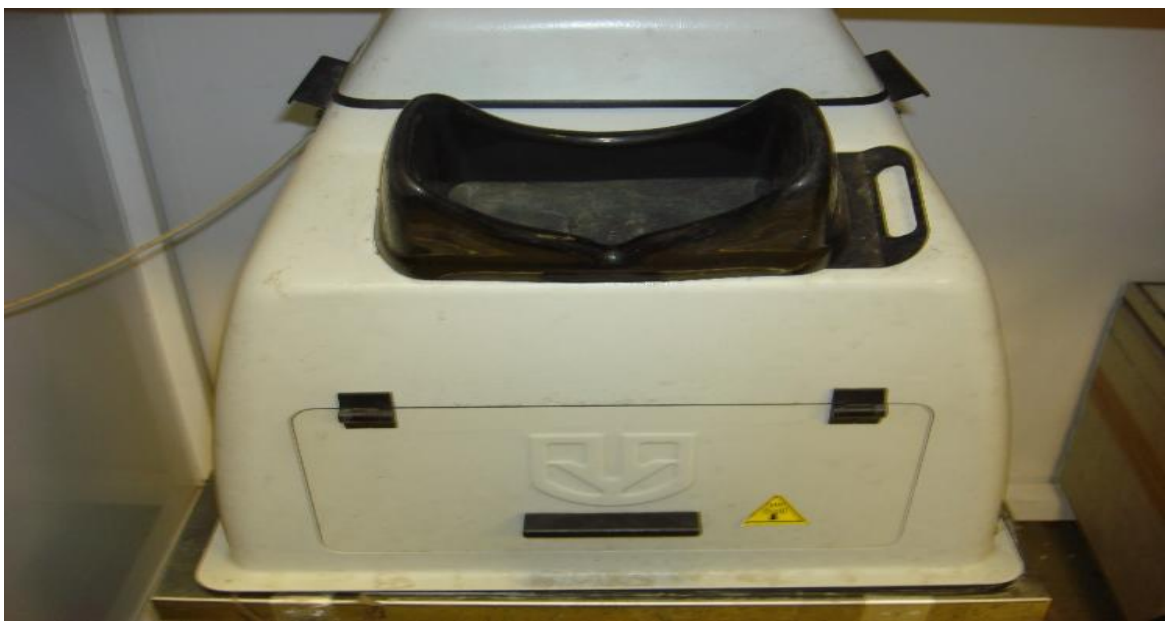

Fig-4: Shows the UV light cabinet 


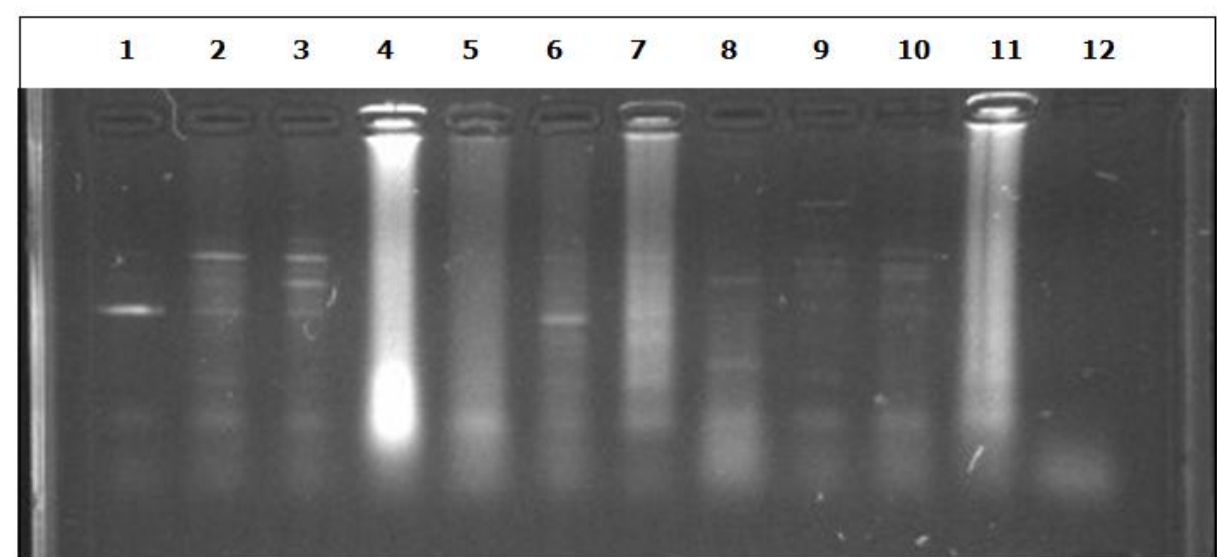

Fig-5: Polymerase Chain Reaction run on a $1.5 \%$ w/v agarose gel, 50 Volts, stained with Ethidium Bromide. DNA size marker is a commercial $173 \mathrm{bp}$. The position of the wells and direction of DNA migration is noted. The numbers of samples in an image indicates the serial number of patients in a Hospital. The pictorial show samples No. $2,3,6 \& 7$ are positive; 1 is ( positive control ), $5,8,9, \&$ 10 are negative ; 12 is (Negative control) but 4,11 aren't consider due to smearing.

\section{DISCUSSION}

In this study evaluation of FOB strips conducted by matched the result of FOB test strips with Z.N and polymerase chain reaction (PCR) techniques. Also there is no so much published data about the use FOB strips in detection of occult blood in TB patients, but such technique have been widely used in similar occasions in the patients with ulcer, urinary tract infection, as mentioned by [4]. Chi-square used, it revealed that, there was association between the uses of FOB strip and the established methods for detection of the pulmonary tuberculosis patients.

The FOB strips were matched to Z.N techniques and it shown that $12(18 \%)$ of cases had the disease while truly had a disease and $41(61 \%)$ of cases were disease by using FOB test while did not have a disease by using Z.N technique, and 14(21\%) of cases were freely of a disease by both methods.

10 specimens out of 41 cases performed by PCR, it shown that $4(40 \%)$ of cases truly had a disease while $6(60 \%)$ of cases were free of the disease. When it was considered in every 10 cases $\{$ Z.N (-ve), FOB $(+v e)\}$ there were 4 cases positive for the disease, so in 41 cases there were 16 were had a disease and by addition of these 16 cases to whom a diseased, it was became $28(42 \%)$ of cases were truly positive while by subtraction these 16 cases from 41 'cases were became $25(37 \%)$ of cases were positive by FOB test and negative by Z.N techniques, but the number of people who did not have the disease became constant 14(21\%).

\section{CONCLUSION AND RECOMMENDATIONS}

From the obtaining results and after comparing the results of FOB with the results of PCR. Obviously, the FOB strips used as screening test for the pulmonary tuberculosis patients. If the test is positive need confirm by a well-established methods like PCR techniques. Further studies required with large sample size and with several diagnostic methods.

\section{REFERENCES}

1. Davis, J. L., Turimumahoro, P., Meyer, A. J., Ayakaka, I., Ochom, E., Ggita, J., ... \& Fair, E. (2019). Home-based tuberculosis contact investigation in Uganda: a household randomised trial. ERJ open research, 5(3), 00112-2019.

2. Ferrara, G., Losi, M., \& Meacci, M. (2005). Routine Hospital Use of A new Commercial Whole Blood Interferon-(gamma) Assay for the Diagnosis of Tuberculosis Infection. Am J Respir Crit Care Med. 1.172(5):631-635.

3. El Sony, A. (2000). Manual Of National Tuberculosis Control $2^{\text {nd }}$ Ed, Khartoum - Sudan, $1-50$.

4. Syed, A. A., Khatoon, B. A., \& Silwadi, M. F. (2001). New reagents for detection of faecal occult blood. Journal of pharmaceutical and biomedical analysis, 24(4), 581-586. 